\title{
Two Monetary Models with Alternating Markets*
}

\author{
Gabriele Camera $^{\dagger} \quad$ YiLi Chien ${ }^{\ddagger}$
}

This version: October 2013

\begin{abstract}
We examine two monetary models with periodic interactions in centralized and decentralized markets: the cash-in-advance model and the model in Lagos and Wright (2005). Given conformity of preferences, technologies and shocks, both models reduce to a single difference equation. In stationary equilibrium, such equations coincide when the price distortion present in one model, due to Nash bargaining, is replicated in the other using a tax on cash revenues. In that case, the quantitative implications for the welfare cost of inflation in each model are also comparable. Differences in the model's performance reduce to differences in the pricing mechanism assumed to govern those transactions that must be settled with the exchange of cash.
\end{abstract}

Keywords: cash-in-advance, matching, microfoundations, money, inflation JEL codes: E1, E4, E5

\section{Introduction}

The question "what's the best approach to modeling money?" is one of those that economists have struggled with for a while. Three decades ago, some viewed the overlapping generations framework as the only satisfactory approach to modeling money [7], while others saw merits from placing real balances in the utility function

\footnotetext{
*We thank an associate editor and two referees for helpful suggestions that improved the exposition of the paper, Casper deVries, seminar participants at the European University Institute, the 2012 Econometric Society North American Summer Meetings, as well as discussant (M. Hagedorn) and seminar participants in the $43^{\text {rd }}$ Konstanz Seminar on Monetary Theory and Monetary Policy. G. Camera acknowledges partial research support through the NSF grant CCF-1101627. Correspondence address: Gabriele Camera, Economic Science Institute, Chapman University, One University dr., Orange, CA 92866; e-mail: camera@chapman.edu.

${ }^{\dagger}$ Economic Science Institute, Chapman University; e-mail: camera@chapman.edu.

${ }^{\ddagger}$ Research Division, Federal Reserve Bank of St. Louis; e-mail: yilichien@gmail.com.
} 
and noted that such a device could be used to unify several results in the literature $[5,15]$. These days, proponents of the framework in [9] (LW model, hereafter) sharply criticize other approaches [17], while proponents of models with nominal price rigidities note how the approach is helpful for policy analysis [6]. One could say that the "best approach to modeling money" debate is alive and well.

We contribute to such academic conversation by examining two microfounded, general equilibrium monetary models: the model in [9], which has attracted recent attention, and the cash-in-advance model, a reduced-form approach in the tradition of [10 14] often criticized by the LW model's advocates. The investigation involves juxtaposing the models' equilibrium allocations and quantitative implications for the welfare cost of inflation. Such an exercise is meaningful for several reasons.

Advocates of the LW model underscore its appeal as a tool for analysis because, unlike reduced-form models, the role of money is made explicit [17, p.267], which is a nice feature. Yet, the cash-in-advance and LW models also exhibit key similarities, from a modeling standpoint. In both models agents synchronously alternate between a centralized market (CM) and a decentralized market (DM); consumption utility depends on where the purchase is settled, in the DM or CM; and asset trading decisions (adjustments of money balances, in particular) are made before a random shock is observed; [12, p.10-11] and [9, pp.462-66]. Given these similarities, the natural question is then: do these theoretical platforms predict different equilibrium allocations? If so, what model features are responsible for such disparities?

Proponents of the LW model have also argued that, in addition to its theoretical appeal, the model can make a significant difference for quantitative results; it can generate higher welfare costs of inflation than reduced-form models [9, p.463-4]. The open question is: are reduced-form models, such as cash-in-advance, generally incapable of producing similar quantitative results, and why?

We proceed as follows. Section 2 lays out the cash-in-advance framework following [12], which has an explicit and transparent description of the physical environ- 
ment. Section 3, reports the main mathematical relationships describing equilibrium allocations in the LW model and identifies the price distortion due to nonlinear pricing. Unlike the cash-in-advance model, in the LW model Nash bargaining determines prices in some transactions (which must be settled with the exchange of money) but not others; hence, a price distortion exists depending on the buyer's bargaining power. Subsequently, the two frameworks are placed on equal footing in terms of preferences, technologies, and shocks. A way to introduce price distortions in the cash-in-advance model without altering its fundamental structure is illustrated, which involves a tax on cash revenues. At this point, the equations describing equilibrium allocations in the cash-in-advance model are derived.

The literature based on the LW model has almost entirely focused on stationary equilibrium. We find that the equations characterizing stationary competitive equilibrium in the cash-in-advance model coincide with the equations that characterize stationary equilibrium in the LW model when sellers have no bargaining power. This also holds when sellers do have some bargaining power, when the price distortion from Nash bargaining is replicated in the other model via a tax on cash revenues (equivalently, a sales tax on cash purchases). Such correspondence between equations immediately extends outside of steady-state, if sellers have no bargaining power and workers have isoelastic preferences; otherwise, the equations do not generally correspond. Hence, there may exist dynamical equilibria which are not the same in the two models.

Before concluding with Section 4 we propose a quantitative exercise, showing that the welfare costs of inflation in the cash-in-advance model match those in the LW model. The lesson is that differences in the models' main equations reduce to differences in the pricing mechanism assumed to govern those transactions that must be settled with the exchange of cash. For comparable preferences, technologies and shocks, differences in performance can be traced to the price distortion from 
bargaining, not to trade frictions. ${ }^{1}$

\section{A cash-in-advance model}

This section discusses a standard general-equilibrium macroeconomic environment with incomplete markets. It is a compact version of the model in [12], where money is introduced by means of cash-in-advance constraints. The model adopts the convention that agents periodically alternate between centralized and decentralized markets, which is also found in the LW model.

Time is discrete and infinite, denoted $t=0,1, \ldots$ There is a constant population composed of a continuum of infinitely-lived agents, who are ex-ante homogeneous and expected utility maximizers. Preferences are defined over non-storable produced goods and labor. Each agent owns equal shares in a representative firm that produces goods using the concave technology $F$, which has labor as the only factor of production.

In a period, traders alternate synchronously between centralized and decentralized markets. Each period is divided into two subperiods, say, morning and afternoon. A decentralized market is open in the morning, while a centralized market is open in the afternoon. To introduce money, it is assumed that some of the morning trades must be settled immediately with the exchange of money (= cash trades) while others can be settled in the afternoon (= credit trades). Goods purchased with cash are distinct from goods purchased on credit, called goods 1 and 2, respectively. Money is injected through lump-sum transfers by a central bank.

Let $s_{t}$ denote a shock realized at the start of $t$. The shock which affects the households' ability to consume and produce cash goods is drawn from a time-invariant set. Let $\left\{s_{t}\right\}_{t=0}^{\infty}$ denote a path of shocks and let $S^{t}=\left(s_{1}, \ldots, s_{t}\right)$ denote a history of

\footnotetext{
${ }^{1}$ Interestingly, the study in [16] reports that the welfare cost of moderate inflation that can be attributed to monetary frictions alone in the LW model is zero. In [3], based on the LW model, the welfare cost of inflation in 23 OECD countries falls if the Nash bargaining price distortion is removed.
} 
shocks (from the set of all possible histories), which is known prior to all period $t$ trading. Let $f^{t}\left(S^{t}\right)$ denote the density of the history $S^{t}$. Neither $F$ nor the money supply process depend on $S^{t}{ }^{2}$ Events on date $t$ evolve as follows.

Morning of $t$ (三 decentralized market) : The shock $s_{t}$ is observed. Households and firms trade goods 1 and 2, and labor. Households hold $M_{t}\left(S^{t-1}\right)$ money and buy $c_{1 t}\left(S^{t}\right)$ goods in exchange for money (= cash goods), buy $c_{2 t}\left(S^{t}\right)$ goods on credit (=credit goods) and supply $h_{t}\left(S^{t}\right)$ labor to the firm on credit. The firm demands $h_{t}^{F}\left(S^{t}\right)$ labor, buying it on credit, and supplies $F\left(h_{t}^{F}\left(S^{t}\right)\right)$ goods. Credit trades are settled in the afternoon of $t$.

Afternoon of $t$ (三 centralized market) : Credit trades executed in the morning of $t$ are settled. Firms pay wages for work supplied in the morning and pay dividends out of morning profits. Households pay for credit goods bought in the morning. The central bank retires the old money supply $\bar{M}_{t-1}$ and issues a new money supply $\bar{M}_{t}$ through lump-sum money transfers $\Theta_{t}$ to households. Trade on a financial market also takes place: households trade state-contingent claims to money to be delivered in the afternoon of $t+1$. Household exits the period holding $M_{t+1}\left(S^{t}\right)$ money.

\subsection{Firm and households' optimal choices}

On date $t$, given history $S^{t}$, the constraint of the firm is

$$
F\left(h_{t}^{F}\left(S^{t}\right)\right)=c_{1 t}^{F}\left(S^{t}\right)+c_{2 t}^{F}\left(S^{t}\right)
$$

where $c_{1 t}^{F}\left(S^{t}\right)$ and $c_{2 t}^{F}\left(S^{t}\right)$ denote cash and credit goods. Because cash and credit goods are distinct, let $p_{j t}\left(S^{t}\right)$ denote the nominal spot price of good $j=1,2$ and let $w_{t}\left(S^{t}\right)$ be the nominal spot wage on $t$. Nominal profits (net dollar inflows) on the

\footnotetext{
${ }^{2} \mathrm{~A}$ shock can also be added in the afternoon market, but since there are no such shocks in the LW model, that case is not studied here. The order of opening of the markets can also be inverted, without loss in generality.
} 
morning of $t$ are

$$
p_{1 t}\left(S^{t}\right) c_{1 t}^{F}\left(S^{t}\right)+p_{2 t}\left(S^{t}\right) c_{2 t}^{F}\left(S^{t}\right)-w_{t}\left(S^{t}\right) h_{t}^{F}\left(S^{t}\right)
$$

which are distributed as dividends in the afternoon.

Since the firm sells for cash and for credit, payments accrue as follows: in the morning, it receives cash payments for cash-goods sales, and in the afternoon it receives payments for the morning's credit sales. Let $q_{t}\left(S^{t}\right)$ denote the date-0 price of a claim to one dollar delivered in the afternoon of $t$, contingent on $S^{t}$ (= state-contingent nominal bond). The firm's date-0 profit-maximization problem is: given state-contingent prices $q_{t}\left(S^{t}\right)$, choose sequences of output and labor $\left(c_{1 t}^{F}\left(S^{t}\right), c_{2 t}^{F}\left(S^{t}\right), h_{t}^{F}\left(S^{t}\right)\right)$ to solve

$$
\begin{array}{ll}
\text { Maximize: } & \sum_{t=0}^{\infty} \int q_{t}\left(S^{t}\right)\left\{p_{1 t}\left(S^{t}\right) c_{1 t}^{F}\left(S^{t}\right)+p_{2 t}\left(S^{t}\right) c_{2 t}^{F}\left(S^{t}\right)-w_{t}\left(S^{t}\right) h_{t}^{F}\left(S^{t}\right)\right\} d S^{t} \\
\text { subject to: } & c_{1 t}^{F}\left(S^{t}\right)+c_{2 t}^{F}\left(S^{t}\right)=F\left(h_{t}^{F}\left(S^{t}\right)\right) .
\end{array}
$$

Substituting for $c_{1 t}^{F}\left(S^{t}\right)$ from the constraint, the FOCs for all $t, S^{t}$ are

$$
\begin{array}{ll}
h_{t}^{F}\left(S^{t}\right): & p_{1 t}\left(S^{t}\right) F^{\prime}\left(h_{t}^{F}\left(S^{t}\right)\right)-w_{t}\left(S^{t}\right)=0 \\
c_{2 t}^{F}\left(S^{t}\right): & p_{1 t}\left(S^{t}\right)-p_{2 t}\left(S^{t}\right)=0 .
\end{array}
$$

Consequently, for all $t, S^{t}$ we have $p_{1 t}\left(S^{t}\right)=p_{2 t}\left(S^{t}\right)=p_{t}\left(S^{t}\right)$ and

$$
p_{t}\left(S^{t}\right) F^{\prime}\left(h_{t}^{F}\left(S^{t}\right)\right)=w_{t}\left(S^{t}\right)
$$

An agent who contracts on date 0 maximizes the expected utility

$$
\sum_{t=0}^{\infty} \beta^{t} \int U\left(c_{1 t}\left(S^{t}\right), c_{2 t}\left(S^{t}\right), h_{t}\left(S^{t}\right)\right) f^{t}\left(S^{t}\right) d S^{t}
$$

where we assume $U$ is a real-valued function, twice continuously differentiable in each argument, strictly increasing in $c_{j}$, decreasing in $h$, and concave. Maximization is subject to two constraints. One is the cash in advance constraint

$$
p_{1 t}\left(S^{t}\right) c_{1 t}\left(S^{t}\right) \leq M_{t}\left(S^{t-1}\right) \quad \text { for all } t \text { and } S^{t}
$$


where $M_{t}\left(S^{t-1}\right)$ are money balances held at the start of $t$, brought in from the afternoon of $t-1$, when the shock $s_{t}$ was not yet realized. Given this uncertainty, money may be held for the purpose of conducting transactions and for precautionary reasons.

The other constraint is the date-0 nominal intertemporal budget constraint:

$$
\begin{aligned}
\sum_{t=0}^{\infty} \int & \left\{q _ { t } ( S ^ { t } ) \left[p_{1 t}\left(S^{t}\right) c_{1 t}\left(S^{t}\right)+p_{2 t}\left(S^{t}\right) c_{2 t}\left(S^{t}\right)-w_{t}\left(S^{t}\right) h_{t}\left(S^{t}\right)-M_{t}\left(S^{t-1}\right)\right.\right. \\
& \left.\left.+M_{t+1}\left(S^{t}\right)-\Theta_{t}\right]\right\} d S^{t} \leq \Pi+\bar{M}
\end{aligned}
$$

The date-0 sources of funds are $\bar{M}$ initial money holdings (=initial liabilities of the central bank) and the firm's nominal value $\Pi$. The left hand side is the date -0 present value of net expenditure. It is calculated by considering the price of money delivered in the afternoon of $t, q_{t}\left(S^{t}\right)$. There are two elements:

1. Morning net expenditure: $w_{t}\left(S^{t}\right) h_{t}\left(S^{t}\right)$ wages earned, paid in the afternoon; $M_{t}\left(S^{t-1}\right)-p_{1 t}\left(S^{t}\right) c_{1 t}\left(S^{t}\right)$ unspent balances available in the afternoon; $p_{2 t}\left(S^{t}\right) c_{2 t}\left(S^{t}\right)$ purchases of credit goods settled in the afternoon. These funds are available in the afternoon of $t$, where the date-0 value of one dollar is $q_{t}\left(S^{t}\right)$.

2. Afternoon net expenditures: the household receives $\Theta_{t}$ transfers and exits the period holding $M_{t+1}\left(S^{t}\right)$ money balances, so net expenditure is $M_{t+1}\left(S^{t}\right)-\Theta_{t}$, with date-0 value $q_{t}\left(S^{t}\right)$.

Given that values can be history-dependent, we integrate over $S^{t}$.

Consumers choose sequences of state-contingent consumption, labor and money 
holdings $c_{1 t}\left(S^{t}\right), c_{2 t}\left(S^{t}\right), h_{t}\left(S^{t}\right)$, and $M_{t+1}\left(S^{t}\right)$ to maximize the Lagrangian:

$$
\begin{aligned}
L:= & \sum_{t=0}^{\infty} \beta^{t} \int U\left(c_{1 t}\left(S^{t}\right), c_{2 t}\left(S^{t}\right), h_{t}\left(S^{t}\right)\right) f^{t}\left(S^{t}\right) d S^{t}+\lambda(\Pi+\bar{M}) \\
& -\lambda \sum_{t=0}^{\infty} \int\left\{q _ { t } ( S ^ { t } ) \left[p_{1 t}\left(S^{t}\right) c_{1 t}\left(S^{t}\right)+p_{2 t}\left(S^{t}\right) c_{2 t}\left(S^{t}\right)-w_{t}\left(S^{t}\right) h_{t}\left(S^{t}\right)\right.\right. \\
& \left.\left.-M_{t}\left(S^{t-1}\right)+M_{t+1}\left(S^{t}\right)-\Theta_{t}\right]\right\} d S^{t} \\
& +\sum_{t=0}^{\infty} \int \mu_{t}\left(S^{t}\right)\left[M_{t}\left(S^{t-1}\right)-p_{1 t}\left(S^{t}\right) c_{1 t}\left(S^{t}\right)\right] d S^{t}
\end{aligned}
$$

where $\mu_{t}\left(S^{t}\right)$ is the Kühn-Tucker multiplier on the cash constraint on $t$, given $S^{t}$.

Omitting the arguments from $U$ and $f$ where understood, in an interior optimum the FOCs for all $t$ and $S^{t}$ are:

$$
\begin{array}{ll}
c_{1 t}\left(S^{t}\right): & \beta^{t} U_{1} f^{t}\left(S^{t}\right)-\lambda p_{1 t}\left(S^{t}\right) q_{t}\left(S^{t}\right)-\mu_{t}\left(S^{t}\right) p_{1 t}\left(S^{t}\right)=0 \\
& p_{1 t}\left(S^{t}\right) c_{1 t}\left(S^{t}\right) \leq M_{t}\left(S^{t-1}\right) \\
c_{2 t}\left(S^{t}\right): & \beta^{t} U_{2} f^{t}\left(S^{t}\right)-\lambda p_{2 t}\left(S^{t}\right) q_{t}\left(S^{t}\right)=0 \\
h_{t}\left(S^{t}\right): & \beta^{t} U_{3} f^{t}\left(S^{t}\right)+\lambda w_{t}\left(S^{t}\right) q_{t}\left(S^{t}\right)=0 \\
M_{t+1}\left(S^{t}\right): & -\lambda q_{t}\left(S^{t}\right)+\lambda \int q_{t+1}\left(S^{t+1}\right) d s_{t+1}+\int \mu_{t+1}\left(S^{t+1}\right) d s_{t+1}=0 .
\end{array}
$$

Given $p_{2 t}\left(S^{t}\right)=p_{1 t}\left(S^{t}\right)=p\left(S^{t}\right)$ and (4) we get

$$
\begin{gathered}
\frac{U_{3}}{U_{2}}=F^{\prime}\left(h_{t}\left(S^{t}\right) ; S^{t}\right) \text { for all } t, S^{t} \\
\frac{U_{1}}{U_{2}}=\frac{\lambda q_{t}\left(S^{t}\right)+\mu_{t}\left(S^{t}\right)}{\lambda q_{t}\left(S^{t}\right)} \text { for all } t, S^{t} .
\end{gathered}
$$

\subsection{Risk-free rate and Central Bank constraint}

Fix $t$ and $S^{t}$. The (reciprocal of the) nominal risk-free interest rate on a bond sold in the afternoon of $t$ is $\frac{1}{1+r_{t}\left(S^{t}\right)}$. This is the price of a claim to money (bought on date 0 ) delivered in the afternoon of $t+1$ conditional on $S^{t}$ (but not on $s_{t+1}$ ) divided by 
the price of a claim to money delivered in the afternoon of $t$ conditional on $S^{t}$ :

$$
\frac{1}{1+r_{t}\left(S^{t}\right)}:=\frac{\int q_{t+1}\left(S^{t+1}\right) d s_{t+1}}{q_{t}\left(S^{t}\right)}=\frac{\lambda \int q_{t+1}\left(S^{t+1}\right) d s_{t+1}}{\lambda \int q_{t+1}\left(S^{t+1}\right) d s_{t+1}+\int \mu_{t+1}\left(S^{t+1}\right) d s_{t+1}},
$$

where the second step comes from the last line in (6). ${ }^{3}$

From (7), the interest rate makes households indifferent between buying money or risk-free bonds in the afternoon of $t$. With cash the consumer can buy either cashor credit-goods in $t+1$; by holding bonds, he can only buy credit goods, as bonds mature in the afternoon of $t+1$. So, the interest rate compensates consumers for the bond's illiquidity, which is why $\mu_{t+1}$ appears in the denominator of (8). Substituting $q_{t}\left(S^{t}\right)=\left(1+r_{t}\left(S^{t}\right)\right) \int q_{t+1}\left(S^{t+1}\right) d s_{t+1}$ in the last line of (6) we get

$$
\left(1+r_{t}\left(S^{t}\right)\right) \int q_{t+1}\left(S^{t+1}\right) d s_{t+1}=\int q_{t+1}\left(S^{t+1}\right) d s_{t+1}+\frac{1}{\lambda} \int \mu_{t+1}\left(S^{t+1}\right) d s_{t+1} .
$$

This is simply an indifference condition between buying an illiquid bond or holding money. The expected benefit from buying a risk-free bond in the afternoon of $t$ that pays one dollar in the afternoon of $t+1$ is $\left(1+r_{t}\left(S^{t}\right)\right) \int q_{t+1}\left(S^{t+1}\right) d s_{t+1}$. Money has the lower expected value $\int q_{t+1}\left(S^{t+1}\right) d s_{t+1}$, but provides the liquidity premium $\frac{1}{\lambda} \int \mu_{t+1}\left(S^{t+1}\right) d s_{t+1}$ because, unlike the bond, a dollar worth of money can be spent in the morning of $t+1$ to buy cash goods.

Let $\bar{M} \geq 0$ be the initial money supply. In the afternoon of $t$, the central bank issues $\bar{M}_{t+1}$ money, valued at $q_{t}\left(S^{t}\right)$ in date-0 prices, and retires it in the afternoon of $t+1$, when the expected value of money is $\int q_{t+1}\left(S^{t+1}\right) d s_{t+1}$. Money is injected via lump-sum transfers $\Theta_{t}$ valued at $q_{t}\left(S^{t}\right)$. The date-0 budget constraint is

$$
\bar{M}=\sum_{t=0}^{\infty} \int\left\{\bar{M}_{t+1}\left[q_{t}\left(S^{t}\right)-\int q_{t+1}\left(S^{t+1}\right) d s_{t+1}\right]-\Theta_{t} q_{t}\left(S^{t}\right)\right\} d S^{t} .
$$

Equivalently, the flow constraint $\bar{M}_{t+1}-\bar{M}_{t}=\Theta_{t}$ for all $t, S^{t}$ identify monetary policy.

\footnotetext{
${ }^{3}$ No-arbitrage requires that expenditures in period 0 are equivalent. The household can spend $q_{t}\left(S^{t}\right) \frac{1}{1+r_{t}\left(S^{t}\right)}$ to buy $\frac{1}{1+r_{t}\left(S^{t}\right)}$ delivered on $t$ conditional on $S^{t}$, and then reinvest on $t$ the receipts in a risk-free bond to get 1 good on date $t+1$. Alternatively, the agent can spend $\int q_{t+1}\left(S^{t+1}\right) d s_{t+1}$ on date 0 to have one unit on date $t+1$, given $S^{t}$.
} 


\section{Juxtaposing the two models}

To compare the LW model and the cash-in-advance model, we utilize the feature that the LW model can be reduced to a single difference equation [9, p. 469].

\subsection{The main equation in the $\mathrm{LW}$ model}

Agents in [9] alternate between two markets: decentralized (DM) and centralized $(\mathrm{CM})$. First, the DM opens and DM goods are traded and then the CM opens and CM goods are traded. CM markets are Walrasian; in the DM there is pairwise trade with Nash bargaining and an agent has equal probability $\delta \leq 1 / 2$ (using our notation see also the Appendix) to buy with money or to sell for money, so the ratio of buyers to sellers is one (assume no barter). Preferences are additively separable with quasilinear labor disutility:

$$
U\left(c_{1}, c_{2}, h_{1}, h_{2}\right)=u_{1}\left(c_{1}\right)-\eta\left(h_{1}\right)+u_{2}\left(c_{2}\right)-h_{2},
$$

where $h_{1}$ and $h_{2}$ denote labor effort in $\mathrm{DM}$ and $\mathrm{CM}, c_{1}$ and $c_{2}$ denote consumption in DM and CM. It is assumed that $u_{1}, u_{2}, \eta$ are twice continuously differentiable, strictly increasing, $u_{1}$ and $u_{2}$ are concave, $\eta$ is convex and $u_{1}(0)=\eta(0)=0$; furthermore, there exists $c_{j}^{*} \in \mathbb{R}_{++}$for $j=1,2$ such that $u_{1}^{\prime}\left(c_{1}^{*}\right)=\eta^{\prime}\left(c_{1}^{*}\right)$ and $u_{2}^{\prime}\left(c_{2}^{*}\right)=1$ with $u_{2}\left(c_{2}^{*}\right)>c_{2}^{*}$.

We now discuss equilibrium in the LW model. ${ }^{4}$ From [9, p.469], on each $t$ equilibrium consumption of $\mathrm{CM}$ goods satisfies

$$
u_{2}^{\prime}\left(c_{2}\right)=1 .
$$

Let $\theta \in(0,1]$ denote the buyer's bargaining power. From [9, eq. (17)], in equilibrium

\footnotetext{
${ }^{4}$ The equilibrium concept is a "blend of traditional Arrow-Debreu components describing aggregates as functions of time $t$ and recursive components describing individuals' problems as functions of $t$ and individual state variables" [9, footnote 3$]$.
} 
$p_{1 t} c_{1 t}=M_{t}$ where DM consumption satisfies

$$
\frac{1}{p_{2 t}}=\frac{\beta}{p_{2, t+1}}\left[\delta u_{1}^{\prime}\left(c_{1, t+1}\right) \frac{1}{z^{\prime}\left(c_{1, t+1} ; \theta\right)}+1-\delta\right],
$$

with $p_{2 t}=\frac{M_{t}}{z\left(c_{1 t} ; \theta\right)}$ and, using $[9$, eq. (8)] and omitting the time subscript

$$
z\left(c_{1} ; \theta\right):=\frac{\theta \eta\left(c_{1}\right) u_{1}^{\prime}\left(c_{1}\right)+(1-\theta) u_{1}\left(c_{1}\right) \eta^{\prime}\left(c_{1}\right)}{\theta u_{1}^{\prime}\left(c_{1}\right)+(1-\theta) \eta^{\prime}\left(c_{1}\right)} .
$$

Equations (10) and (11) determine equilibrium consumption in the LW model.

Consider a stationary equilibrium in which money grows at a constant rate $\gamma \geq \beta$, and consumption and real money balances are constant. The inflation rate also equals $\gamma, r_{t}=r=\frac{\gamma}{\beta}-1$ and the LW model reduces to the equation

$$
\frac{u_{1}^{\prime}\left(c_{1}\right)}{z^{\prime}\left(c_{1} ; \theta\right)}=1+\frac{r}{\delta}
$$

The key observation is that the DM pricing schedule is nonlinear due to bargaining, so the marginal benefit from spending one more dollar is $\frac{u_{1}^{\prime}\left(c_{1}\right)}{z^{\prime}\left(c_{1} ; \theta\right)}$; instead, we would have $\frac{u_{1}^{\prime}\left(c_{1}\right)}{p_{1} / p_{2}}$ under linear pricing, with $p_{1} / p_{2}=\eta^{\prime}\left(c_{1}\right) \leq z^{\prime}\left(c_{1} ; \theta\right) .{ }^{5}$ Such price distortion is measured by the ratio

$$
\psi\left(c_{1}, \theta\right):=\frac{\eta^{\prime}\left(c_{1}\right)}{z^{\prime}\left(c_{1} ; \theta\right)},
$$

where $\psi\left(c_{1}, 1\right)=1$ (no distortion) and $\psi\left(c_{1}, \theta\right)<1$ for $\theta<1$. Figure 1 illustrates that the price distortion depends on $\theta$.

\subsection{Model consistency}

To present a meaningful comparison, preferences, technologies, and shocks in the cashin-advance model must conform to those in the LW model. This section discusses how this logical coherence is achieved.

Technologies: Let $F(h)=h$ as in the LW model. Since the marginal product of

\footnotetext{
${ }^{5}$ If $\theta=1$, then $z^{\prime}=\eta^{\prime}$. If $\theta<1$ we have $z^{\prime}>\eta^{\prime}$. Indeed, $u_{1}^{\prime} \geq \eta^{\prime}$; hence, $\theta u_{1}^{\prime}+(1-\theta) \eta^{\prime}<u_{1}^{\prime}$. From the definition of $z\left(c_{1} ; \theta\right)$ we have $z^{\prime}=\frac{u_{1}^{\prime}}{\theta u_{1}^{\prime}+(1-\theta) \eta^{\prime}} \eta^{\prime}+A$ where $A>0$.
} 


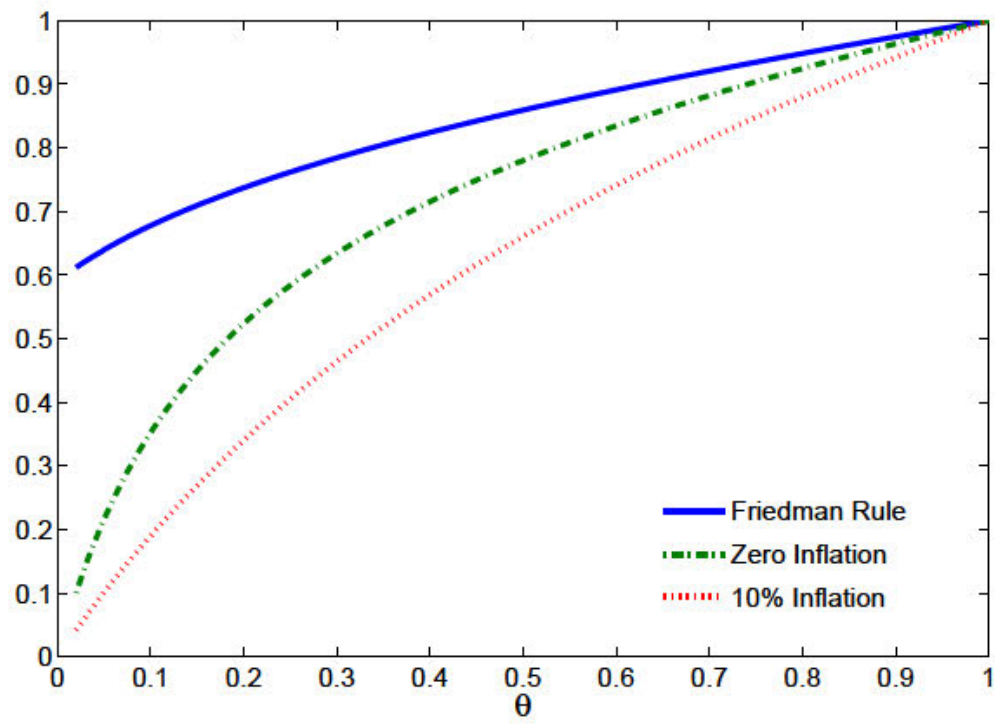

Figure 1: The price distortion in the LW model

Notes to Figure 1: The three curves correspond to $\psi\left(c_{1} ; \theta\right)$ assuming - as in the calibration in [9]-that $\eta^{\prime}=1, u_{1}\left(c_{1}\right)=\frac{\left(c_{1}+b\right)^{1-a}-b^{1-a}}{1-a}, a=0.3, b=0, \delta=0.5$ and $r=1.04 \gamma-1$, with $\gamma=\beta$ (=Friedman rule), $\gamma=1$ (=zero inflation) and $\gamma=1.1$ (=10\% inflation). 
labor is fixed and independent of $S^{t}$, it is convenient (and without loss in generality) to interpret production of goods 1 and 2 as occurring in two batches. The firm chooses $h_{j t}^{F}$ (= labor demanded to produce good $\left.j=1,2\right)$ and $c_{j t}^{F}$ (= supply) to solve

$$
\begin{array}{ll}
\text { Maximize: } & \sum_{t=0}^{\infty} q_{t}\left(S^{t}\right)\left[p_{1 t}\left(S^{t}\right) c_{1 t}^{F}+p_{2 t}\left(S^{t}\right) c_{2 t}^{F}-w_{1 t}\left(S^{t}\right) h_{1 t}^{F}-w_{2 t}\left(S^{t}\right) h_{2 t}^{F}\right] \\
\text { subject to: } & c_{2 t}^{F}=h_{1 t}^{F} \text { and } c_{1 t}^{F}=h_{1 t}^{F} .
\end{array}
$$

Substituting the constraints, the FOCs are

$$
p_{j t}\left(S^{t}\right)-w_{j t}\left(S^{t}\right)=0 \quad \text { for all } t \text { and } j=1,2 \text {. }
$$

Prices equal marginal cost and profits are zero, so $\Pi=0$.

Preferences and shocks: Let $s_{t}$ be an i.i.d. shock such that in each $t$ a randomly drawn portion $\delta \in(0,1)$ of households desires good 1 and produces it. Hence,

$$
f^{t}\left(S^{t}\right)=f^{t}\left(s_{t} ; S^{t-1}\right)=f\left(s_{t}\right) f^{t-1}\left(S^{t-1}\right) \text { for all } t \geq 0,
$$

where $f$ denotes the distribution of the date- $t$ shock. Here $s_{t}=\left(s_{t}^{i}\right)_{\text {all } i}$ where

$$
s_{t}^{i}=\left\{\begin{array}{ll}
1 & \text { with probability } \delta \\
0 & \text { with probability } 1-\delta
\end{array} \text { for all } t \geq 0 \text { and all agents } i\right.
$$

where $s_{t}^{i}=0$ means that household $i$ neither derives utility from consuming good 1 nor can produce it. For any agent $i$, the marginal probabilities are thus $\int f\left(s_{t}\right) \mathbf{1}_{\left\{s_{t}^{i}=0\right\}} d s_{t}=$ $1-\delta$ and $\int f\left(s_{t}\right) \mathbf{1}_{\left\{s_{t}^{i}=1\right\}} d s_{t}=\delta$.

Assume preferences (9), where $h_{j t}^{i}$ is labor supplied by household $i$ to produce good $j=1,2$. For household $i$ on date $t$ we have:

$$
U\left(c_{1 t}, c_{2 t}, h_{1 t}, h_{2 t}\right)=\left[u_{1}\left(c_{1 t}^{i}\right)-\eta\left(h_{1 t}^{i}\right)\right] \mathbf{1}_{\left\{s_{t}^{i}=1\right\}}+u_{2}\left(c_{2 t}^{i}\right)-h_{2 t}^{i} .
$$

Price distortion: A parsimonious way to match the price distortion $\psi\left(c_{1}, \theta\right)$ is to introduce a proportional tax either on sales or purchases involving cash goods. For example, assume that a share $1-\tau$ of revenue from cash-sales taken as given must 
be rebated back to the firm's owners, lump-sum. For mnemonic ease, we refer to $\tau$ as the parameter of a "cash-revenue tax." The parameter $\tau$ distorts the relative price of cash and credit goods, without altering the model's structure or equilibrium concept. In particular, the firm's problem is unchanged: we must simply substitute $p_{1 t} \tau c_{1 t}^{F}$ for $p_{1 t} c_{1 t}^{F}$, so that the first order condition for cash goods becomes $p_{1 t} \tau=w_{1 t}$ and $\frac{p_{1 t}}{p_{2 t}}=\frac{w_{1 t}}{w_{2 t}} \times \frac{1}{\tau}$. Because the buyer spends $p_{1 t} c_{1 t}$ and the seller receives $p_{1 t} \tau c_{1 t}$, we can interpret $p_{1 t} c_{1 t}(1-\tau)$ as a sales tax and $\frac{1}{\tau}-1$ as the sales tax rate on cash transactions. Viewed in this manner, introducing the tax parameter $\tau$ does not amount to adding an unrealistic feature to the model; in fact, sales taxes are commonplace at the state and local level in many countries.

\subsection{The main result}

The literature based on the LW model has almost entirely focused on stationary equilibrium (one exception is [8]). Consequently, we focus on stationary competitive equilibrium in the cash-in-advance model; later, we discuss what happens outside the steady state.

Proposition 1. Consider the cash-in-advance model with preferences, technologies, and shocks as in the LW model, and a cash-revenue tax with parameter $\tau$. If $\tau=\psi\left(c_{1}, \theta\right)$, then the equations characterizing stationary competitive equilibrium in the cash-in-advance model coincide with equations (10) and (12), which characterize stationary equilibrium in the LW model. The cash-in-advance model can generate the same welfare costs of inflation as the LW model.

To provide support for this finding we start by deriving the main equations of the cash-in-advance model. Consider a generic household $i$. On date 0 , he can spend $q_{t}\left(S^{t}\right)$ to buy a claim to one unit of money delivered in the afternoon of $t$, contingent on the history $S^{t}$. Let $q_{t}$ be the price of money delivered on $t$ unconditional on $S^{t}$ (= a risk-free discount bond). No-arbitrage requires equal expenditures, i.e., 
$q_{t}=\int q_{t}\left(S^{t}\right) d S^{t}$. It also implies ${ }^{6}$

$$
q_{t}\left(S^{t}\right)=q_{t} f^{t}\left(S^{t}\right)
$$

To keep the discussion focused, suppose $\tau=1$ (no tax, no price distortion). The problem of agent $i$ is still given by (5), where we substitute $q_{t}\left(S^{t}\right)=q_{t} f^{t}\left(S^{t}\right), U$ from (14), separate the labor choices for each production batch, and set $\Pi=0$ in the intertemporal budget constraint. ${ }^{7}$ Household $i$ chooses sequences $c_{1 t}\left(S^{t}\right), c_{2 t}\left(S^{t}\right)$, $h_{1 t}\left(S^{t}\right), h_{2 t}\left(S^{t}\right)$ and $M_{t+1}\left(S^{t}\right)$ to maximize:

$$
\begin{aligned}
L^{i}:= & \sum_{t=0}^{\infty} \beta^{t} \int U\left(c_{1 t}\left(S^{t}\right), c_{2 t}\left(S^{t}\right), h_{1 t}\left(S^{t}\right), h_{2 t}\left(S^{t}\right)\right) f^{t}\left(S^{t}\right) d S^{t}+\lambda \bar{M} \\
& -\lambda \sum_{t=0}^{\infty} \int q_{t} f^{t}\left(S^{t}\right)\left\{\left[p_{1 t}\left(S^{t}\right) c_{1 t}\left(S^{t}\right)+p_{2 t}\left(S^{t}\right) c_{2 t}\left(S^{t}\right)-w_{1 t}\left(S^{t}\right) h_{1 t}\left(S^{t}\right)\right.\right. \\
& \left.\left.-w_{2 t}\left(S^{t}\right) h_{2 t}\left(S^{t}\right)-M_{t}\left(S^{t-1}\right)+M_{t+1}\left(S^{t}\right)-\Theta_{t}\right]\right\} d S^{t} \\
& +\sum_{t=0}^{\infty} \int \mu_{t}\left(S^{t}\right)\left[M_{t}\left(S^{t-1}\right)-p_{1 t}\left(S^{t}\right) c_{1 t}\left(S^{t}\right)\right] d S^{t}
\end{aligned}
$$

The FOCs, for all $t$ and $S^{t}$, are

$$
\begin{array}{ll}
c_{1 t}\left(S^{t}\right): \quad & \beta^{t} u_{1}^{\prime}\left(c_{1 t}\left(S^{t}\right)\right) f^{t}\left(S^{t}\right)-\lambda p_{1 t}\left(S^{t}\right) q_{t} f^{t}\left(S^{t}\right)-\mu_{t}\left(S^{t}\right) p_{1 t}\left(S^{t}\right)=0 \quad \text { for } s_{t}^{i}=1 \\
& p_{1 t}\left(S^{t}\right) c_{1 t}\left(S^{t}\right) \leq M_{t}\left(S^{t-1}\right), \\
c_{2 t}\left(S^{t}\right): \quad & \beta^{t} u_{2}^{\prime}\left(c_{2 t}\left(S^{t}\right)\right)-\lambda p_{2 t}\left(S^{t}\right) q_{t}=0, \\
h_{1 t}\left(S^{t}\right): \quad & -\beta^{t} \eta^{\prime}\left(h_{1 t}\left(S^{t}\right)\right)+\lambda w_{1 t}\left(S^{t}\right) q_{t}=0, \text { for } s_{t}^{i}=1, \\
h_{2 t}\left(S^{t}\right): \quad & -\beta^{t}+\lambda w_{2 t}\left(S^{t}\right) q_{t}=0, \\
M_{t+1}\left(S^{t}\right): \quad & \lambda q_{t} f^{t}\left(S^{t}\right)=\lambda q_{t+1} f^{t}\left(S^{t}\right)+\int \mu_{t+1}\left(S^{t+1}\right) d s_{t+1} .
\end{array}
$$

\footnotetext{
${ }^{6}$ If $q_{t}\left(S^{t}\right)<q_{t} f^{t}\left(S^{t}\right)$, then $q_{t}\left(\tilde{S}^{t}\right)>q_{t} f^{t}\left(\tilde{S}^{t}\right)$ for some other state $\tilde{S}^{t}$ since $\int f^{t}\left(S^{t}\right) d S^{t}=1$. In this case, the agent could make large profits with zero net investment by (i) purchasing claims that pay in state $S^{t}$ at a cheap price $q_{t}\left(S^{t}\right)$, while selling risk-free claims at price $q_{t}$; and (ii) selling claims that pay in state $\tilde{S}^{t}$ at a steep price $q_{t}\left(\tilde{S}^{t}\right)$, while buying risk-free claims at price $q_{t}$. Thus non-contingent claims would not be traded at price $q_{t}$, which is a contradiction.

${ }^{7}$ In competitive equilibrium the firm makes zero profits and since $\tau=1$ households get no rebate on cash purchases. Therefore, the value of holding the firm, П, must be zero.
} 
The last line is derived using $q_{t+1} f^{t+1}\left(S^{t+1}\right)=q_{t+1} f\left(s_{t+1}\right) f^{t}\left(S^{t}\right)$ and noticing that $\int q_{t+1} f\left(s_{t+1}\right) f^{t}\left(S^{t}\right) d s_{t+1}=q_{t+1} f^{t}\left(S^{t}\right)$ because $\int f\left(s_{t+1}\right) d s_{t+1}=1$ by definition.

From $-\beta^{t}+\lambda w_{2 t}\left(S^{t}\right) q_{t}=0$ we have that $w_{2 t}$ is independent of $S^{t}$ and therefore, using the firm's optimality conditions, $p_{2 t}$ is independent of $S^{t}$. Since $-\beta^{t}+\lambda w_{2 t} q_{t}=0$ and $w_{2 t}=p_{2 t}$ (from the firm's problem), the optimal choice of credit goods in (16) satisfies $\beta^{t} u_{2}^{\prime}\left(c_{2 t}\left(S^{t}\right)\right)=\lambda p_{2 t} q_{t}$; this implies

$$
u_{2}^{\prime}\left(c_{2 t}\left(S^{t}\right)\right)=1 \text { for all } t, S^{t}
$$

so $c_{2 t}\left(S^{t}\right)=c_{2}$ for all $t, S^{t}$ and all agents $i$. This coincides with (10).

Consider cash goods. Their consumption is heterogeneous because for if $s_{t}^{i}=0$ for agent $i$, then $c_{1 t}^{i}\left(S^{t}\right)=0$; this also implies $\mu_{t}\left(S^{t}\right)=0$ for agent $i$ because this agent's cash constraint does not bind. Now consider $s_{t}^{i}=1$. We prove that if an agent desires to consume cash goods, then the quantity consumed is independent of the history of shocks $S^{t}$ and of the identity of the agent, $i$.

Lemma 1. Consider any agent $i$ and let $s_{t}^{i}=1$. In competitive equilibrium:

1. If $\mu_{t}\left(S^{t}\right)=0$, then $c_{1 t}\left(S^{t}\right)=c_{1}$ for all $t, S^{t}$, with $\frac{u_{1}^{\prime}\left(c_{1}\right)}{\eta^{\prime}\left(c_{1}\right)}=1$.

2. If $\mu_{t}\left(S^{t}\right)>0$, then $c_{1 t}\left(S^{t}\right)=\frac{M_{t}}{p_{1 t}}=c_{1 t}$ for all $t, S^{t}$, where $c_{1 t}$ satisfies

$$
\frac{\beta}{p_{2, t+1}}\left[\delta u_{1}^{\prime}\left(c_{1, t+1}\right) \frac{1}{\eta^{\prime}\left(c_{1, t+1}\right)}+1-\delta\right]-\frac{1}{p_{2 t}}=0 \text { for all } t
$$

with $p_{2 t}=\frac{M_{t}}{\eta^{\prime}\left(c_{1 t}\right) c_{1 t}}$.

\section{Proof of Lemma 1. See Appendix}

On date $t$, not everyone consumes cash goods $\left(c_{1 t}^{i}=0\right.$ when $\left.s_{t}^{i}=0\right)$ but those who do consume an identical quantity $c_{1 t}$, independent of the history of shocks. Since $U$ is linear in $h_{2}$, everyone saves the same amount of money $M_{t}\left(S^{t-1}\right)=M_{t}$ on $t-1$, there is a degenerate distribution of money, and prices are history-independent. Clearly, if 
$\mu_{t}=0$, then $u_{1}^{\prime}=\eta^{\prime}$ and the agent consumes the efficient quantity $c_{1 t}=c_{1}^{*}$. Otherwise, $u_{1}^{\prime}>\eta^{\prime}$ and $c_{1 t}=\frac{M_{t}}{p_{1 t}}<c_{1}^{*}$ (first and third equations in (16) with $p_{1 t}=w_{1 t}$ ).

Using the risk-free interest rate defined in (8), we have

$$
\frac{1}{1+r_{t}}=\frac{\int q_{t+1}\left(S^{t+1}\right) d s_{t+1}}{q_{t}\left(S^{t}\right)}=\frac{q_{t+1} f^{t}\left(S^{t}\right)}{q_{t} f^{t}\left(S^{t}\right)}=\frac{\beta}{\pi_{t}} .
$$

The second equality holds by substituting $q_{t}\left(S^{t}\right)=q_{t} f^{t}\left(S^{t}\right)$ and noting that $q_{t+1} f^{t+1}\left(S^{t+1}\right)=$ $q_{t+1} f\left(s_{t+1}\right) f^{t}\left(S^{t}\right)$ so that $\int q_{t+1} f\left(s_{t+1}\right) f^{t}\left(S^{t}\right) d s_{t+1}=q_{t+1} f^{t}\left(S^{t}\right)$ because $\int f\left(s_{t+1}\right) d s_{t+1}=$ 1. To perform the final step substitute $\frac{\beta^{t} u_{2}^{\prime}\left(c_{2 t}\right)}{\lambda p_{2 t}}=q_{t}$ from $(16)$, use $u_{2}^{\prime}\left(c_{2 t}\right)=1$, and define the gross inflation rate $\pi_{t}:=\frac{p_{2, t+1}}{p_{2 t}}$.

Now let $M_{t+1}=\gamma M_{t}$ and consider stationary equilibrium with $\frac{M_{t+1}}{p_{2, t+1}}=\frac{M_{t}}{p_{2 t}}, \frac{p_{2, t+1}}{p_{2 t}}=$ $\gamma$ and $r_{t}=r=\frac{\gamma}{\beta}-1$ for all $t$. Equation (17) yields

$$
\frac{u_{1}^{\prime}\left(c_{1}\right)}{\eta^{\prime}\left(c_{1}\right)}=\frac{r}{\delta}+1
$$

The only difference between (18) and (12) is given by the price distortion in the LW model. Due to linear pricing, the marginal benefit from spending one more dollar on cash goods is $\frac{u_{1}^{\prime}\left(c_{1}\right)}{p_{1} / p_{2}}$ where $p_{1} / p_{2}=\eta^{\prime}\left(c_{1}\right)$ in equilibrium.

Now note that equation (18) coincides with (12) when $\theta=1$, since $z^{\prime}=\eta^{\prime}$; intuitively, sellers are price-takers in both models. ${ }^{8}$ Otherwise, when $\theta<1$, it does not because $z^{\prime}>\eta^{\prime}$, i.e., Nash bargaining induces a price distortion. This is evidence that the two frameworks' differences, in terms of stationary equilibrium allocations, reduce to differences in assumptions about the pricing mechanism that governs those transactions that must be settled with the exchange of money. One wonders whether the distortion generated by the Nash bargaining solution can be reproduced by introducing a cash-revenue tax in the cash-in-advance model.

Re-introduce the cash-revenue tax parameter $\tau \leq 1$. The households' problem is (15). ${ }^{9}$ The FOCs are in (16), so the model still reduces to the difference equation

${ }^{8}$ Clearly, the two equations coincide if DM goods are traded on competitive markets, as in $[1,3,18]$.

${ }^{9}$ The only difference is $\Pi$ appears in the agent's budget constraint — as it did in (5) - due to 
(17). However, in stationary equilibrium relative prices are $\frac{p_{1}}{p_{2}}=\frac{\eta^{\prime}\left(h_{1}\right)}{\tau}$, so we obtain

$$
\frac{u_{1}^{\prime}\left(c_{1}\right)}{\eta^{\prime}\left(c_{1}\right) / \tau}=1+\frac{r}{\delta}
$$

This equation coincides with (12) if $\tau=\psi\left(c_{1}, \theta\right)$, which is when the cash-revenue tax in equilibrium reproduces the price distortion induced by Nash bargaining. The lesson is that, in stationary equilibrium, differences in the frameworks' main equations reduce to the price distortion due to bargaining. Such distortion can be replicated in the cash-in-advance model with an appropriate "tax" on revenues from cash transactions.

The result partially extends to non-stationary equilibrium.

Corollary 1. If $\eta$ satisfies $\frac{d \ln \eta(h)}{d \ln h}=\kappa>0$ and $\theta=1$, then the equations characterizing non-stationary competitive equilibrium in the cash-in-advance model coincide with (10) and (11), which characterize non-stationary equilibrium in the LW model.

The result immediately follows from Lemma 1. Rewrite equation (17) as

$$
\frac{\eta^{\prime}\left(c_{1 t}\right) c_{1 t}}{M_{t}}=\beta \frac{\eta^{\prime}\left(c_{1, t+1}\right) c_{1, t+1}}{M_{t+1}}\left[\frac{u_{1}^{\prime}\left(c_{1, t+1}\right)}{\eta^{\prime}\left(c_{1, t+1}\right)} \delta+1-\delta\right],
$$

and note that it coincides with (11) when $\theta=1$ and $\frac{d \ln \eta(h)}{d \ln h}=\kappa$, because $p_{2 t}=\frac{M_{t}}{\eta\left(c_{1 t}\right)}$ (since $\left.z\left(c_{1} ; 1\right)=\eta\left(c_{1}\right)\right)$ and $\eta^{\prime}\left(c_{1}\right) c_{1}=\kappa \eta\left(c_{1}\right)$. Both $\eta$ linear and the common isoelastic formulation $\eta(h)=\frac{h^{x}}{x}$ for $x>1$ satisfy $\frac{d \ln \eta(h)}{d \ln h}=\kappa$. The correspondence between the equations characterizing non-stationary allocations in the two models breaks down when $\theta<1$. Again, the difference in allocations reduce to differences in assumptions about the pricing mechanism that governs those transactions that must be settled with the exchange of money. ${ }^{10}$ Hence, there may exist equilibria which are not the same in the two models.

lump-sum rebates from the firm. In equilibrium we have $\Pi=\sum_{t=0}^{\infty} \int q_{t} f^{t}\left(S^{t}\right) T_{t} d S^{t}$ where the rebate $T_{t}=p_{1, t}(1-\tau) c_{1 t} \delta$ on $t$.

${ }^{10}$ The equations characterizing non-stationary allocations coincide when DM goods are priced competitively. 


\subsection{Quantitative comparison}

To evaluate possible quantitative differences between the cash-in-advance model and the LW model, we adopt the specification in [9, Table 1], which considers stationary equilibrium in the model calibrated to annual U.S. data.

Preferences over goods are defined by

$$
u_{1}\left(c_{1}\right)=\frac{\left(c_{1}+b\right)^{1-a}-b^{1-a}}{1-a} \quad \text { and } \quad u_{2}\left(c_{2}\right)=B \log c_{2}
$$

for some $a>0, b \in(0,1)$ and $B>0$. Consumption $c_{2}$ satisfies (10), labor disutility satisfies $\eta^{\prime}=1$, so $c_{1}$ satisfies

$$
\frac{\gamma}{\beta}-1=\delta\left[\tau u_{1}^{\prime}\left(c_{1}\right)-1\right]
$$

Define ex-ante welfare

$$
\mathcal{W}_{\gamma}:=u_{2}\left(c_{2}\right)-c_{2}+\delta\left[u_{1}\left(c_{1}(\gamma)\right)-c_{1}(\gamma)\right]
$$

Considering the compensating variation $\Delta$, welfare at zero inflation is denoted

$$
\mathcal{W}_{1}:=u_{2}\left(\Delta c_{2}\right)-c_{2}+\delta\left[u_{1}\left(\Delta c_{1}(1)\right)-c_{1}\right]
$$

The welfare cost of $\gamma-1$ inflation is the value $1-\Delta$ where $\Delta$ satisfies $\mathcal{W}_{1}-\mathcal{W}_{\gamma}=0$.

In $[9$, p.475], $\theta$ is calibrated to match the average price markup in U.S. data; the markup is $\frac{z\left(c_{1} ; \theta\right)}{c_{1} \eta^{\prime}\left(c_{1}\right)}$, i.e., the ratio of the DM good price $p_{1}$ to marginal cost. ${ }^{11}$ In our model the markup is $\frac{p_{1}}{w_{1}}=\frac{1}{\tau} \equiv \frac{z^{\prime}\left(c_{1} ; \theta\right)}{\eta^{\prime}\left(c_{1}\right)}$ because we match the price distortion in the LW model by setting $\tau=\psi\left(c_{1} ; \theta\right)$ and use the calibrated value of $\theta$ from the LW model. Hence, the markups in the two model generally do not coincide.

Table 1 compares results for the cash-in-advance and the LW model, in five different cases. Panel 1 shows that the cash-in-advance model can yield identical consump-

\footnotetext{
${ }^{11}$ It varies with the bargaining power and it generally varies with $c_{1}$ (but not always; consider $\eta(h)=\frac{h^{x}}{x}, x \geq 1$ and $\theta=1$ ). In the calibration labor disutility is linear so the markup coincides with the relative price $\frac{p_{1}}{p_{2}}$, which is $\frac{z\left(c_{1} ; \theta\right)}{c_{1}}$.
} 
tion as in [9, Table 1]. Panel 2 reports average price markups, at each inflation rate; the average markups are comparable. Fixing the parameter $\theta$, average markups increase with inflation in both models; if we interpret $\frac{1}{\tau}-1$ as the sales tax rate on cash trades, then the model does not imply unreasonable average sales tax rates. ${ }^{12}$ Panel 3 shows that the cash-in-advance model can yield identical welfare cost of inflation as in the LW model.

Table 1: Quantitative comparison with the LW model

\begin{tabular}{lccccc}
\hline \hline Parameter & case 1 & case 2 & case 3 & case 4 & case 5 \\
\hline$\delta(\equiv \alpha \sigma)$ & .31 & .5 & .5 & .5 & .5 \\
$a(\equiv \eta)$ & .27 & .16 & .30 & .30 & .30 \\
$B$ & 2.13 & 1.97 & 1.91 & 1.78 & 1.78 \\
$\theta$ & 1 & 1 & .5 & .343 & 1 \\
\hline Inflation & Panel 1: Equilibrium $c_{1}$ & & \\
\hline 0.1 & .243 & .206 & .143 & .094 & .523 \\
0 & .638 & .618 & .442 & .296 & .821 \\
$\beta^{-1}-1$ & 1 & 1 & .779 & .568 & 1 \\
\hline \multicolumn{7}{c}{ Panel 2: Average markup } \\
\hline 0.1 & 0 & 0 & $\{.056, .050\}$ & $\{.049, .050\}$ & 0 \\
0 & 0 & 0 & $\{.141, .123\}$ & $\{.123, .114\}$ & 0 \\
$\beta^{-1}-1$ & 0 & 0 & $\{.213, .183\}$ & $\{.196, .172\}$ & 0 \\
\hline \multicolumn{7}{c}{ Panel 3: Welfare cost of $10 \%$ inflation } \\
\hline 0 & .014 & .014 & .032 & .046 \\
$\beta^{-1}-1$ & .016 & .016 & .042 & .068 & .013 \\
\hline \hline
\end{tabular}

Notes to Table 1: The comparison involves the calibration in [9, Table 1]. The Parameters column reports our notation (the corresponding notation from [9], when different from ours, is reported in parentheses). In both models $c_{2}=B$ in equilibrium and $\beta^{-1}=1.04$. The inflation rate is $\gamma-1$. When numbers are different in the two models we report them as the pair $\{\mathrm{LW}$, cash-in-advance $\}$.

\footnotetext{
${ }^{12}$ The share of DM output in the LW model is easily constructed, given that in the calibrated model everyone is matched in the DM ( $\alpha=1$ in the LW model). DM output is $\delta c_{1}$ and CM output is $c_{2} \equiv B$, in the calibrated model. Hence, total output is $Y=\delta c_{1}+B$ and the DM output share is $\frac{\delta c_{1}}{Y}$ (it increases as inflation falls because real money balances increase); this also gives us the share of cash goods to total goods in the cash-in-advance model. This share is used to calculate average markups. In the calibration, when $\theta=0.5$ we have $\tau=\psi\left(c_{1} ; \theta\right)=.719, .846, .928$ for, respectively, $\gamma=.1,0, \frac{1-\beta}{\beta}$; the corresponding average sales tax rates are: $.025, .037, .034$. Instead, when $\theta=0.343$, we have $\tau=\psi\left(c_{1} ; \theta\right)=.511, .672, .802$; the corresponding average sales tax rates are: $.014, .019, .013$. As inflation decreases the markup in cash trades, $\frac{1}{\tau}$, falls; yet, the average markup increases because the share of cash goods to total output rises.
} 
In a nutshell, the cash-in-advance model can replicate the same, large welfare cost of inflation found in the LW mod7el, once price distortions are accounted for (cases 3-4). This suggests that the difference in the assumed pricing mechanisms is primarily what lies behind the dissimilarities in quantitative results between the two models, and not the explicit microfoundation for money in the LW model as opposed to the reduced-form approach of the other model.

\section{Final comments}

We have examined two monetary models characterized by periodic interactions in centralized and decentralized markets: the cash-in-advance model, and the model in [9]. Prices are linear in the former but are non-linear in the latter when trades must be settled with the exchange of cash, due to Nash bargaining. Our analysis indicates that this is the one difference that matters.

When the models are placed on equal footing in terms of preferences, technologies and shocks, both models reduce to a single equation describing stationary equilibrium. The equations coincide when sellers have no bargaining power. Otherwise, the equations differ in just one element the price distortion from bargaining. Yet, such distortion can be replicated in the cash-in-advance model using a proportional tax. For simplicity, we have considered a tax on cash revenues, in which case allocations and welfare costs of inflation are comparable in stationary equilibrium.

Our findings neither rely on altering the market structure of the LW model, nor the equilibrium concept or the basic structure of the cash-in-advance model. The analysis should neither be taken to imply that nothing can be done with one model, which could not be done with the other, nor that the models are identical. In fact, our analysis has emphasized the central role played by assumptions about the pricing mechanisms presumed to govern cash-based trades in the two models. 


\section{References}

[1] Berentsen,A., G. Camera and C. Waller (2007). Money, credit, and banking. Journal of Economic Theory 135 (1), 171-195.

[2] Boel P. and G. Camera (2009). Financial sophistication and the distribution of the welfare cost of inflation. Journal of Monetary Economics, 56, 968-978.

[3] Boel P. and G. Camera (2011). The welfare cost of inflation in OECD countries. Macroeconomic Dynamics, 15 (Supplement 2), 217-251.

[4] Chiu, J. and M. Molico (2010). Liquidity, Redistribution, and the Welfare Cost of Inflation. Journal of Monetary Economics 57(4), 428-438.

[5] Feenstra, R. (1986). Functional equivalence between liquidity costs and the utility of money. Journal of Monetary Economics 17, 271-291

[6] Galí J. and Gertler , M. (2007) Macroeconomic Modeling for Monetary Policy Evaluation. Journal of Economic Perspectives 21(4), 25-46

[7] Kareken, J.A. and Wallace, N. (1980) Introduction. In: Kareken, J.A., Wallace, N. (eds.) Models of monetary economies, 1-9. Minneapolis: Federal Reserve Bank of Minneapolis.

[8] Lagos, R., and R. Wright (2003). Dynamics, cycles, and sunspot equilibria in 'genuinely dynamic, fundamentally disaggregative' models of money. Journal of Economic Theory, 109 (2), 156-171.

[9] Lagos, R., and R. Wright (2005). A unified framework for monetary theory and policy analysis. Journal of Political Economy, 113 (3), 463-484.

[10] Lucas, R.E., Jr. (1980). Equilibrium in a pure currency Economy. Economic Inquiry, 18, 203-20. 
[11] Lucas, R.E., Jr. (1982) Interest rates and currency prices in a two-country world. Journal of Monetary Economics, 10, 335-60.

[12] Lucas, R.E., Jr. (1984). Money in a theory of finance. Carnegie-Rochester Conference Series on Public Policy 21, 9-46

[13] Lucas, R.E., Jr. (1986). Principles of fiscal and monetary policy. Journal of Monetary Economics, 17, 117-134.

[14] Lucas, R.E., Jr. and Stokey, N.L. (1983) Optimal fiscal and monetary policy in an economy without capital. Journal of Monetary Economics, 12, 55-93.

[15] McCallum, B.T. (1983). The role of overlapping-generations mondels in monetary economics. Carnegie-Rochester Conference Series on Public Policy 18, 9-44

[16] Rocheteau G. (2012) The cost of inflation: A mechanism design approach. Journal of Economic Theory, 147 (3), 1261-1279

[17] Williamson S. and Wright R. (2010). New Monetarist Economics: Methods. Federal Reserve Bank of St. Louis Review, 92(4), 265-302.

[18] Rocheteau, G. and R. Wright (2005). Money In Search Equilibrium, In Competitive Equilibrium, And In Competitive Search Equilibrium. Econometrica, 73(1), $175-202$ 


\section{Appendix}

\section{Proof of Lemma 1}

Consider an equilibrium with history-independent prices $p_{1 t}\left(S^{t}\right)=p_{1 t}$ and $w_{1 t}\left(S^{t}\right)=$ $w_{1 t}$, as in [9]. ${ }^{13}$ To prove the first part of the Lemma let $s_{t}^{i}=1$ and $\mu_{t}\left(S^{t}\right)=0$. From the first and third expressions in (16) we have

$$
\beta^{t} u_{1}^{\prime}\left(c_{1 t}\left(S^{t}\right)\right)=\lambda p_{1 t} q_{t}=\lambda w_{1 t} q_{t}=\beta^{t} \eta^{\prime}\left(h_{1 t}\left(S^{t}\right)\right), \quad \text { for all } t, S^{t},
$$

From market clearing $h_{1 t}^{F}\left(S^{t}\right)=\delta h_{1 t}\left(S^{t}\right)=\delta c_{1 t}\left(S^{t}\right)=c_{1 t}^{F}\left(S^{t}\right) .{ }^{14}$ Hence, $\frac{u_{1}^{\prime}\left(c_{1 t}\left(S^{t}\right)\right)}{\eta^{\prime}\left(c_{1 t}\left(S^{t}\right)\right)}=1$ for all $t, S^{t}$. That is $c_{1 t}\left(S^{t}\right)=c_{1}$ for all $t$ and all agents $i$ such that $s_{t}^{i}=1$.

To prove the second part of the Lemma let $s_{t}^{i}=1$ and $\mu_{t}\left(S^{t}\right)>0$. Update by one period the first expression in the FOCs (16) to get

$$
\frac{\beta^{t+1}}{p_{1, t+1}} u_{1}^{\prime}\left(c_{1, t+1}\left(S^{t+1}\right)\right) f\left(s_{t+1}\right) f^{t}\left(S^{t}\right)=\lambda q_{t+1} f\left(s_{t+1}\right) f^{t}\left(S^{t}\right)+\mu_{t+1}\left(S^{t+1}\right), \quad \text { if } s_{t+1}^{i}=1
$$

where we substituted $f^{t+1}\left(S^{t+1}\right)=f\left(s_{t+1}\right) f^{t}\left(S^{t}\right)$. Now substitute $c_{1, t+1}\left(S^{t+1}\right)=$ $\frac{M_{t+1}\left(S^{t+1}\right)}{p_{1, t+1}}$ since $\mu_{t+1}\left(S^{t+1}\right)>0$. The expression above has the status of an equality only if $s_{t+1}^{i}=1$. In that case, we can integrate both sides with respect to $s_{t+1}$, conditional on $s_{t+1}^{i}=1$. For the left-hand-side we get

$$
\begin{aligned}
& \frac{\beta^{t+1}}{p_{1, t+1}} \int \mathbf{1}_{\left\{s_{t+1}^{i}=1\right\}} u_{1}^{\prime}\left(c_{1, t+1}\left(S^{t+1}\right)\right) f\left(s_{t+1}\right) f^{t}\left(S^{t}\right) d_{s_{t+1}} \\
& \quad=\frac{\beta^{t+1}}{p_{1, t+1}} u_{1}^{\prime}\left(\frac{M_{t+1}\left(S^{t}\right)}{p_{1, t+1}}\right) \int \mathbf{1}_{\left\{s_{t+1}^{i}=1\right\}} f\left(s_{t+1}\right) f^{t}\left(S^{t}\right) d_{s_{t+1}} \\
& \quad=\frac{\beta^{t+1}}{p_{1, t+1}} u_{1}^{\prime}\left(\frac{M_{t+1}\left(S^{t}\right)}{p_{1, t+1}}\right) f^{t}\left(S^{t}\right) \int \mathbf{1}_{\left\{s_{t+1}^{i}=1\right\}} f\left(s_{t+1}\right) d_{s_{t+1}} \\
& \quad=\frac{\beta^{t+1}}{p_{1, t+1}} u_{1}^{\prime}\left(\frac{M_{t+1}\left(S^{t}\right)}{p_{1, t+1}}\right) f^{t}\left(S^{t}\right) \delta
\end{aligned}
$$

\footnotetext{
${ }^{13}$ Prices and wages will not depend on the history $S^{t}$ here if the distribution of money holdings is degenerate at the start of each period $t$, which we will prove to be the case.

${ }^{14}$ Under linear labor disutility, households are indifferent to how much labor $h_{1}$ they supply at the given wage $w_{1}$. In that case, we consider symmetric choices, i.e., every household supplies the same labor effort. This is as in [9].
} 
For the right-hand-side we get

$$
\begin{aligned}
& \int \mathbf{1}_{\left\{s_{t+1}^{i}=1\right\}}\left[\lambda q_{t+1} f\left(s_{t+1}\right) f^{t}\left(S^{t}\right)+\mu_{t+1}\left(S^{t+1}\right)\right] d s_{t+1} \\
& =\lambda q_{t+1} f^{t}\left(S^{t}\right)+\int \mu_{t+1}\left(S^{t+1}\right) d s_{t+1}-\Phi=\lambda q_{t} f^{t}\left(S^{t}\right)-\Phi
\end{aligned}
$$

where the last step follows from the last line in (16) and

$$
\begin{aligned}
\Phi & :=\int \mathbf{1}_{\left\{s_{t+1}^{i}=0\right\}}\left[\lambda q_{t+1} f\left(s_{t+1}\right) f^{t}\left(S^{t}\right)+\mu_{t+1}\left(S^{t+1}\right)\right] d s_{t+1} \\
& =\int \mathbf{1}_{\left\{s_{t+1}^{i}=0\right\}}\left[\lambda q_{t+1} f\left(s_{t+1}\right) f^{t}\left(S^{t}\right)\right] d s_{t+1}, \quad \text { since } \mu_{t+1}\left(S^{t+1}\right)=0 \text { when } s_{t+1}^{i}=0 \\
& =\lambda q_{t+1} f^{t}\left(S^{t}\right) \int \mathbf{1}_{\left\{s_{t+1}^{i}=0\right\}} f\left(s_{t+1}\right) d s_{t+1} \\
& =\lambda q_{t+1} f^{t}\left(S^{t}\right)(1-\delta), \quad \text { since } \int \mathbf{1}_{\left\{s_{t+1}^{i}=0\right\}} f\left(s_{t+1}\right) d s_{t+1}=1-\delta \\
& =\beta^{t+1} \frac{u_{2}^{\prime}\left(c_{2, t+1}\right)}{p_{2, t+1}} f^{t}\left(S^{t}\right)(1-\delta), \quad \text { from }(16) .
\end{aligned}
$$

Equating the expectations of both sides from (20) and (21) we have

$$
\frac{\beta^{t+1}}{p_{1, t+1}} u_{1}^{\prime}\left(\frac{M_{t+1}\left(S^{t}\right)}{p_{1, t+1}}\right) \delta=\lambda q_{t}-\frac{\Phi}{f^{t}\left(S^{t}\right)}
$$

Substituting $\Phi$ in the equation above we get

$$
\frac{\beta^{t+1}}{p_{1, t+1}} u_{1}^{\prime}\left(\frac{M_{t+1}\left(S^{t}\right)}{p_{1, t+1}}\right) \delta=\lambda q_{t}-\frac{\beta^{t+1} u_{2}^{\prime}\left(c_{2, t+1}\right)}{p_{2, t+1}}(1-\delta),
$$

or equivalently, since $u_{2}^{\prime}\left(c_{2, t+1}\right)=1$ for all $t+1$ and $S^{t+1}$, we have

$$
\beta^{t+1}\left[u_{1}^{\prime}\left(\frac{M_{t+1}\left(S^{t}\right)}{p_{1, t+1}}\right) \frac{\delta}{p_{1, t+1}}+\frac{1-\delta}{p_{2, t+1}}\right]=\lambda q_{t} .
$$

This implies that if $s_{t+1}^{i}=1$, then $c_{1, t+1}\left(S^{t+1}\right)=\frac{M_{t+1}\left(S^{t}\right)}{p_{1, t+1}}=\frac{M_{t+1}}{p_{1, t+1}}=c_{1, t+1}$ for all $t$ and $S^{t}$ and for all agents $i$, because $q_{t}$ is independent of $S^{t}$. The distribution of money is degenerate because there are no wealth effects due to the linear disutility from producing credit goods. Households equally reach the same cash holdings by adjusting their labor supply $h_{2}^{i}$. By market clearing, $h_{2 t}^{F}=\int h_{2 t}^{i} d i=c_{2 t}$ where $h_{2 t}^{i}$ 
satisfies the agents' budget constraint.

Now substitute $\lambda q_{t}=\frac{\beta^{t} u_{2}^{\prime}\left(c_{2 t}\right)}{p_{2 t}}=\frac{\beta^{t}}{p_{2 t}}$ from (16) and write the equation above as (17). Finally, from the firm's problem, we have $\eta^{\prime}\left(h_{1 t}\right)=\frac{w_{1 t}}{w_{2 t}}=\frac{p_{1 t}}{p_{2 t}}$.

\section{Comparing notations in [9] and in our model}

In [9], $U(X)$ is the utility received from consuming $X \mathrm{CM}$ goods $\left(u_{2}\left(c_{2}\right)\right.$ in our notation). The technology to produce CM goods is linear and the disutility from labor is linear. In the DM, a portion $\alpha \sigma$ ( $\delta$ in our notation) of agents desires to consume (but cannot produce) and an identical portion can produce but does not consume; $u(q)$ is the utility received from consuming $q$ DM goods $\left(u_{1}\left(c_{1}\right)\right.$ in our notation); $c$ is the disutility from labor in the DM ( $\eta$ in our notation); the nominal price is $\frac{d}{q}$ per unit of consumption ( $p_{1}$ in our notation); the real price is $\frac{\phi d}{q}$, where $\phi$ is $\frac{1}{p_{2}}$ in our notation. With binding cash constraints $d=M$ and $\frac{\phi M}{q}$ where $M$ is the agent's money holdings. We also have $\phi M \equiv z(q)$ where $0<\theta \leq 1$ is the buyer's bargaining power. The nominal interest rate is $i$ ( $r$ in our notation). 